\title{
High-Throughput Optimization of Effective Microbes Nutrient Formulation via Automated Media Optimization System (AMOS)
}

\author{
A I Saharuddin ${ }^{1}$, N Z M N Rashid ${ }^{1}$, N S Mohd Noor ${ }^{1}$, N S Abdul Rahman ${ }^{1}$, A Ismail ${ }^{1}$, \\ W R Wan Abdul Razak ${ }^{1}$, F Pardi ${ }^{1}$, A H Jawad ${ }^{2}$, K Ismail ${ }^{2}$, K A Radzun ${ }^{1 *}$ \\ ${ }^{1}$ School of Biology, Faculty of Applied Sciences, Universiti Teknologi MARA, 40450 Shah Alam, Selangor, Malaysia \\ ${ }^{2}$ School of Chemistry, Faculty of Applied Sciences, Universiti Teknologi MARA, 40450 Shah Alam, Selangor, Malaysia \\ *Corresponding author E-mail: khairuladzfa@salam.uitm.edu.my
}

\begin{abstract}
Fortification of effective microbes (EM) such as Pediococcus acidilactici and photosynthetic bacteria in fertilizer and animal feed exhibiting effective outcomes in enhancing crops and livestock production as well as upholds sustainable agriculture concept. Howe ver, the productivity of the EM biomass stocks is unsurpassed to the demand due to non-optimized media. In this study, two sets of nutrient pair comprising of beef extract-manganese and yeast extract-glucose for $P$. acidilactici and photosynthetic bacteria respectively were studied. The optimum media formulated was based on the highest growth rate in 96-microwell plate system were subsequently tested in $1 \mathrm{~L}$ cultures volume for EM biomass production. Results showed that growth rate and dry weight of $P$. acidilactici in media supplemented with $64 \mathrm{~g} / \mathrm{L}$ beef extract $\left(0.145 \mathrm{~h}^{-1}, 0.243 \mathrm{~g}\right)$ and $0.28 \mathrm{~g} / \mathrm{L}$ manganese $\left(0.1134 \mathrm{~h}^{-1}, 0.32 \mathrm{~g}\right)$ were higher compared to control medium with an increment of $17.39 \%$ and $54.59 \%$ biomass productivity as compared to MRS medium respectively. Meanwhile, the growth rate and dry weight for Photosynthetic bacteria in media supplemented with $6.63 \mathrm{~g} / \mathrm{L}$ glucose $\left(0.2538 \mathrm{~h}^{-1}, 0.167 \mathrm{~g}\right)$ and $0.44 \mathrm{~g} / \mathrm{L}$ yeast extract $(0.2733$ $\mathrm{h}^{-1}, 0.163 \mathrm{~g}$ ) recorded $11.3 \%$ and $8.73 \%$ biomass productivity increment in comparison to the HCH medium.
\end{abstract}

Keywords: Automated Media Screening System; Biomass; Growth; Microbes; Nutrient.

\section{Introduction}

Effective microorganism (EM) is a mixture of liquid inoculant bacterial culture comprising of photosynthesizing bacteria, lactic acid bacteria, yeast, actinomycetes and fermenting fungi that can upsurge the microbial diversity in the soil ecosystem. Most of EM has the ability to encourage the mineralization of soil organic matter. Soil embedded with EM plays a vital role in nourishing the soil fertility in continuous intensive cropping system which helps to sustain the productivity of the crops. A good-conditioned soil can prevent the plant from being infected by disease-causing parasites and pathogenic microorganisms. There are many benefits of using EM including enhancing the process of decomposing organic microorganism and other compound other than suppressing soil-borne pathogens. Furthermore, it acts as an environmentally remedial and eco-friendly cleaning process because of their specific characteristics - not genetically engineered, non-pathogenic, and no involvement of chemical synthesize [1,2]. Each EM has its significant role, for example, lactic acid bacteria produced lactic acid from the breakdown of carbohydrate and sugar. The sterilizing effects of lactic acid protect the plant against nematode associated disease [1]. Furthermore, the photosynthetic bacteria play a leading role in EM biotech industry as they are commonly used as an additive for biofertilizer to improve the quality of the crops. This is due to the ability of photosynthetic bacteria in nitrogen fixation, sulphide oxidation and carbon sequestration in various natural environments [3].
Probiotics bacteria is a bacterium that has a fastidious nutritional requirement comprises of complex and rich media for optimal growth [4]. Although in the past there are reports on optimum mediums generated specifically for Pediococcus acidilactici and photosynthetic bacteria, there are still many challenges that have not been specifically addressed or met. This includes the inadequacy on the media preparation parts, costly at the larger scale cultivation, and low biomass productivity. Thus, to ensure maximum productivity and minimize the cost to the lowest possible, another economically effective formulation alternatives are in great demand.

Nutrient modulation is vital to enhance the development of effective microbes, improve the biomass or production of the desired product. The study was conducted to determine the best nutrients and at what concentration. A major element known as macroelements or macronutrients is an essential element that makes up cell constituent. The macronutrient is required in a large amount and commonly help to preserve the cell construction and metabolism. According to Kumar [5], a significant percentages of the bacterial cell biomass is made up of macroelements. These, in general, comprises of oxygen, carbon, nitrogen, hydrogen, sulphur, magnesium, potassium, phosphorus, calcium and iron [6]. The most abundant monosaccharide like glucose has become the best carbon source for many bacteria strains. However, some of the bacteria cannot utilize sugars; therefore, they need carbon source in the form of carbon dioxide, carbonate or bicarbonate. On the contrary, micronutrients are elements that are only needed in a small quantity. They are mainly involved in enzyme functioning and helps in catalytic reactions and maintaining the protein struc- 
ture [5]. Rose, as reported in her studies, has noted a few examples of such elements that include zinc, manganese, copper, cobalt, and molybdenum [7].

Carbon source such as glucose, fructose, bicarbonate, and carbon dioxide are reported to be the component with most biomolecules (approximately $50 \%$ of the ash-free biomass) which can be found in the form of $\mathrm{CO}_{2}$ and other organic form such as acetate which is suitable for photoautotrophic, photoheterotrophic, heterotrophic, and mixotrophic growth regimes. The second abundant element, oxygen, also a component of most biomolecules with an approximately 12 percent to 29 percent [8] of biomass and is an integral part of most biomass components including proteins, carbohydrates, and oils.

Nitrogen sources contain nitrogen elements are growth stimulant for lactic acid bacteria and photosynthetic bacteria [9]. According to Baida [4], nitrogen sources (yeast extract, meat extract) and glucose are a good growth stimulant. The other component acts as a supplement to maintain the best condition for EM's growth. The selection of nitrogen sources is crucial as an increase in percentage yield of nitrogen in the substance gave the more positive outcome. Apart from that, the nitrogen concentrations level is also important because excessive or limitation of $\mathrm{N}$ sources could adversely af fect the cultivation yield, productivity and bacteriocin production of lactic acid bacteria [10]. They also reported that the production of pediocin activity of $P$. acidilactici reached its peak casein peptone medium. According to Polak-Berecka [11], media supplemented with meat extract yielded a slightly higher dry weight compared to other media supplemented with yeast extract and peptone. This is because the amount of total nitrogen percentage per weight is greater in beef extract than the other sources.

Moreover, previous studies have shown the potential benefits of the application of rich $\mathrm{N}$ source, yeast extract toward the microbial cultures as it consists of high protein level, multivitamin B complex and minerals [12]. Zhao [13] also find that the replacement of biotin by yeast extract is a cost-effective practice. Although yeast extract is much economical than biotin, photosynthetic bacteria is much better in terms of productivity. Also, a study done by Madukasi [14] stated that the addition of yeast extract into ammonium supplemented wastewater further increased the cell growth of the Photosynthetic bacteria from $\mathrm{OD}_{660} 1.03$ to 1.502 in the pharmaceutical wastewater test medium. However, a high concentration of yeast extract had no significant effect on cell growth. Although yeast extract contains many B vitamin, it may also act as a source of protein and its use depends on the economic evaluation of the process.

Manganese is a reducing chemical element in a redox reaction in which it oxidizes organic matter, i.e. glucose into $\mathrm{CO}_{2}$ and $\mathrm{CH}_{4}$. It plays a role as an electron acceptor for organic matter oxidation facilitated by effective microbes. Thus, it was used as one of the constituents in bacterial culture medium formulation [15]. Manganese ion was proven to affect the production of lactic acid on the growth of lactic acid bacteria significantly [16].

All bacteria must have an optimized environment to culture effective microbe with an essential source of energy, a source of carbon, and a tolerant range of cultivation conditions such as temperature, and $\mathrm{pH}$ [17]. The optimal growth conditions for $P$. acidilactici are at a temperature of $40^{\circ} \mathrm{C}$ and initial $\mathrm{pH}$ 6.0. It can tolerate progressive changes in $\mathrm{pH}$ in the well-buffered growth medium. It will rapidly deteriorate if $\mathrm{pH}$ changes abruptly and not well buffered. The optimal $\mathrm{pH}$ of the medium for most of the photosynthetic bacteria range between 6.5 to 8.0 [18]. Therefore, the $\mathrm{pH}$ that was set constant at 6.8 and at room temperature.

The robotic nutrient screening system can be used to determine the optimal concentration of tested nutrients (beef extract, manganese, glucose and yeast extract) required by $P$. acidilactici and Photosynthetic bacteria in minimal duration. The automated high throughput robotic system could specifically identify the best nutrient condition and concentration used in this study. A study conducted by Radzun [19], stated that the nutrient screen was designed to provide a miniaturized, high throughput platform for rapid low - cost optimization of the nutrient condition. The medium optimization study of microalgae strains was carried out by employing simple Full - Factorial and Box - Behnken experimental design to improve nutrient composition in the media via this similar system called an Automated Nutrient Screening System (AMNSS). The system is equipped with two screening systems a) Screen 1 (application of simple Full - Factorial to determine different types of $\mathrm{N}$ sources $\left(\mathrm{NaNO}_{3}, \mathrm{NH}_{4} \mathrm{Cl}\right.$, Urea and $\left.\mathrm{NH}_{4} \mathrm{NO}_{3}\right)$ and one phosphate source $\left(\mathrm{KH}_{2} \mathrm{PO}_{4}\right)$ at 5 and 3 different concentrations respectively), and b) Screen 2 (application of Box Behnken Design to determine response surface and main interaction effects of macro and microelements). Consequently, the new formulated medium obtained through this system was compared to the traditional non-optimized media used to grow strains of microalgae [19].

\section{Methodology}

\subsection{Effective microbes culture}

The samples of effective microbe used in this study were Pediococcus acidilactici and photosynthetic bacteria. These bacteria cultures were isolated from the soil sample collected from oil palm plantation of Sabah Softwoods Berhad in Tawau, Sabah, Malaysia The effective microbe cultures were maintained in deMan Rogosa Sharpe (MRS) medium for $P$. acidilactici and nutrient broth (NB) medium for photosynthetic bacteria at Microalgae Research Laboratory, Faculty of Applied Sciences located at the Faculty of Pharmacy Building FF3 UiTM Selangor (Puncak Alam Campus), Selangor, Malaysia. The cultures were incubated at $30^{\circ} \mathrm{C}$, agitated at $80 \mathrm{rpm}$ under continuous white fluorescence lamp around 30 $\mu$ molm ${ }^{-2} \mathrm{~s}^{-1}$ except for $P$. acidilactici under dark condition.

\subsection{Methods}

\subsubsection{Preparation of media}

The control media used in this study were commercial MRS broth (Himedia, India) for the cultivation of P. acidilactici, and $\mathrm{HCH}$ medium was specially formulated for the growth of photosynthetic bacteria. The HCH control medium for the cultivation of photosynthetic bacteria was prepared by adding $1 \mathrm{ml}$ of trace element, $100 \mathrm{ml}$ master stock glucose and $0.4 \mathrm{ml}$ of master stock yeast extract to the prepared basal media. The initial $\mathrm{pH}$ of MRS broth was at $\mathrm{pH} 6.2$ and $\mathrm{pH} 6.8$ for $\mathrm{HCH}$ medium.

The composition of basal media for the Pediococcus acidilactici growth as shown in Table $\mathbf{1}$ below. The master stock preparation of beef extract was prepared by diluting $10 \mathrm{~g}$ of beef extract into $100 \mathrm{ml}$ of distilled water. For the manganese master stock of 0.6 $\mathrm{g} / \mathrm{L}$ manganous chloride tetrahydrate was prepared by diluting $0.012 \mathrm{~g}$ of $\mathrm{MnCl}_{2}$ in $200 \mathrm{ml}$. Then, $1 \mathrm{ml}$ of all the five concentration levels of beef extract and manganous chloride was prepared by serial dilution from each master stock.

Table 1: Basal media composition for Pediococcus acidilactici.

\begin{tabular}{|c|c|c|}
\hline \multicolumn{3}{|c|}{ Basal media composition (g/L) } \\
\hline Nutrients & $\begin{array}{c}\text { Beef extract } \\
\text { optimization } \\
\text { medium }\end{array}$ & $\begin{array}{c}\text { Manganese optimiza- } \\
\text { tion medium }\end{array}$ \\
\hline $\mathrm{MnCl}_{2}$ & - & 0.05 \\
\hline Beef extract & 20.0 & - \\
\hline Peptone & 10.0 & 10.0 \\
\hline $\mathrm{MgSO}_{4}$ & 0.2 & 0.2 \\
\hline $\mathrm{K}_{2} \mathrm{HPO}_{4}$ & 2.0 & 2.0 \\
\hline $\mathrm{Glucose}_{2} \mathrm{H}_{9} \mathrm{NaO}_{5}$ & 20.0 & 20.0 \\
\hline $\mathrm{Yeast} \mathrm{extract} \mathrm{C}_{6} \mathrm{H}_{8} \mathrm{O}_{7}$ & 5.0 & 5.0 \\
\hline
\end{tabular}

Note: All the media were prepared in $200 \mathrm{~mL}$ 
The composition of basal media for photosynthetic bacteria growth as shown in Table 2. The trace elements were mixed together in a $50 \mathrm{ml}$ of the non-sterile bottle. A dilution of $19.8 \mathrm{~g}$ glucose into $500 \mathrm{ml}$ of distilled water was done for the preparation of $0.22 \mathrm{~mol} / \mathrm{L}$ glucose - master stock. For the preparation of master stock of $0.9 \mathrm{~mol} / \mathrm{L}$ yeast extract, a commercial Baker's yeast was obtained. The steps are as follows: 1) dissolving process, 2) autoclaving ( $121^{\circ} \mathrm{C}$ for 15 minutes), 3 ) fast cooling (in ice for 10 minutes), 4) centrifugation (at $14000 \mathrm{rpm}$ for 10 minutes) to separate the cell debris, 5) re-centrifugation to filter the insoluble cell contents. The water-soluble extract was then stored for optimization process via AMOS. Then, $1 \mathrm{ml}$ of all the five concentration levels of glucose and yeast extract was prepared by serial dilution from each master stock.

Table 2: Basal media composition for Photosynthetic bacteria.

\begin{tabular}{|c|c|c|}
\hline \multicolumn{3}{|c|}{ Basal media composition (g/L) } \\
\hline Nutrients & $\begin{array}{l}\text { Glucose opti- } \\
\text { mization } \\
\text { medium }\end{array}$ & $\begin{array}{l}\text { Yeast extract optimiza- } \\
\text { tion medium }\end{array}$ \\
\hline Glucose & $0.22 \mathrm{~mol} / \mathrm{L}$ & - \\
\hline Yeast extract & - & $0.9 \mathrm{~mol} / \mathrm{L}$ \\
\hline $\mathrm{MgSO}_{4}$ & 0.12 & 0.12 \\
\hline $\mathrm{KH}_{2} \mathrm{PO}_{4}$ & 0.5 & 0.5 \\
\hline $\mathrm{K}_{2} \mathrm{HPO}_{4}$ & 0.3 & 0.3 \\
\hline NaEDTA & 0.075 & 0.075 \\
\hline $\mathrm{CaCl}_{2}$ & 0.000676 & 0.000676 \\
\hline$\left(\mathrm{NH}_{4}\right)_{2} \mathrm{SO}_{4}$ & 1.0 & 1.0 \\
\hline \multicolumn{3}{|l|}{ Trace elements } \\
\hline $\mathrm{MnCl}_{2} \cdot 4 \mathrm{H}_{2} \mathrm{O}$ & 1.78 & 1.78 \\
\hline $\mathrm{C}_{6} \mathrm{H}_{5} \mathrm{FeO}_{7}$ & 0.61 & 0.61 \\
\hline $\mathrm{ZnSO}_{4} .7 \mathrm{H}_{2} \mathrm{O}$ & 0.95 & 0.95 \\
\hline $\mathrm{CoCl}_{2} \cdot 6 \mathrm{H}_{2} \mathrm{O}$ & 0.57 & 0.57 \\
\hline $\mathrm{CuSO}_{4} .5 \mathrm{H}_{2} \mathrm{O}$ & 0.6 & 0.6 \\
\hline
\end{tabular}

Note: All the media were prepared in $200 \mathrm{~mL}$

The trace element (one millilitre) and $0.22 \mathrm{~mol} / \mathrm{L}$ of master stock glucose $(100 \mathrm{ml})$ were added to the prepared basal media - a basalglucose medium. Meanwhile, basal medium with yeast extract was prepared by adding the prepared basal media with $1 \mathrm{ml}$ of trace element and $0.4 \mathrm{ml}$ master stock of yeast extract. Then the mixture was swirled until the solution homogenous. The media was set to optimal $\mathrm{pH}$ required by each effective microbes using $1 \mathrm{M} \mathrm{NaOH}$ or $1 \mathrm{M} \mathrm{HCl}$. The final step for media preparation was sterilization via autoclaving at $121^{\circ} \mathrm{C}$ for 15 minutes.

\subsubsection{Medium optimization via AMOS}

An Automated Media Optimization System (AMOS) was used throughout the nutrient screening process. Dilution process was conducted via the used of the robotic nutrient dispensing system. A custom designed Tecan robot (Freedom Evo 150, Tecan Group Ltd., Männedorf, Switzerland) equipped with a liquid handling dispensing arm was used to accurately dispense the nutrient screen matrix solutions into the well of 96-microwell plate, three microplate shakers with built-in LED light, and spectrophotometer for optical density screening [19]. For nutrient optimization, five different concentrations of the beef extract and manganese for Pediococcus acidilactici, and glucose and yeast extract for photosynthetic bacteria were prepared for this activity. The range of nutrient concentrations that were used was half or twice to the average concentration. During this experiment, all media for each concentration were screened in triplicate. The effective microbes sample for the optimization process were taken at starting OD 0.1 (during exponential phase). P. acidilactici and photosynthetic bacteria were manually pipetted into each well of 96-microwell plate together with $10 \mu \mathrm{L}$ phosphate buffer saline (PBS) for maintaining the $\mathrm{pH}$ of the cultures throughout the incubation period.

\subsubsection{Growth rate determination}

The growth rate of effective microbes was analyzed using optical density measurement (OD). The absorbance was spectrophotometrically (Tecan M1000 spectrophotometer) measured at $600 \mathrm{~nm}$ for $P$. acidilactici and $660 \mathrm{~nm}$ for photosynthetic bacteria. The OD reading of bacteria cultures was measured for 48 hours of cultivation starting from 0 hours. Graphs were plotted to observe the bacterial growth pattern and their growth rate. The growth rate was calculated by using the formula:

Growth rate, $\mu\left(\mathbf{h}^{-1}\right)=\frac{2.303(\log \text { OD } 2-\log \text { OD } 1)}{(t 2-t 1)}$,

$\mathrm{OD}_{2}=$ O.D. of time 2

$\mathrm{OD}_{1}=$ O.D. of time 1

$\mathrm{T}_{2}=$ time 2

$\mathrm{T}_{1}=$ time 1

\subsubsection{Dry weight determination}

A $1 \mathrm{~L}$ bacteria culture of the best-optimized media for each element as well as positive control were prepared for 1L flask cultures. After 18 to 24 hours of cultivation for Pediococcus acidilactici and photosynthetic bacteria, the samples were taken out and transferred into sterilized falcon tube. The cells were harvested by centrifugation at $6,000 \mathrm{rpm}$ for 15 minutes. The supernatant was discarded, and pellets were washed three times with distilled water to remove contaminating salt. Then, the pellets were transferred into the pre-weighed bowl and wet weight is measured by using an analytical balance. The steps were repeated for each bacteria culture. The pellets were dried to a constant mass in a drying oven at $70{ }^{\circ} \mathrm{C}$ for 36 hours. The percentage of dry mass was calculated from the collected data.

\subsubsection{Statistical analysis}

Statistical analysis was carried out via SPSS software. Means of triplicates of all tested nutrient at five concentration levels was compared to positive control. The mean data comparison was completed using one-way analysis of variance (ANOVA) at $p \leq$ 0.05 level of significance.

\section{Result and discussion}

\subsection{Medium optimization to enhance the growth of Pediococcus acidilactici using Automated Media Opti- mization System}

The experiment to optimize the medium composition of $P$. acidilactici was conducted to improve the growth of $P$. acidilactici and to attain high production of biomass with minimal cultivation duration to achieve high productivity. The optimized medium composition for culturing $P$. acidilactici was shown in Table 3. The experiments were performed in two days (48 hours) to study the effect of beef extract and manganese (at five concentration levels) on the EM's growth using a modified MRS medium as a basal medium. After 48 hours of incubation via AMOS, the growth rate obtained shows that both tested nutrients (beef extract and manganese) gave a positive effect on the $P$. acidilactici growth performance. As stated by Pathak and Martirosyan [9], C source and $\mathrm{N}$ source were utilized by lactic acid bacteria as their nutritional needs for growth. On the other hand, manganese as micronutrient (nutrient required in micro amount) has a biological function as a structural and catalytic cofactor for proteins which make it as the crucial substance for cellular processes [20]. 
Table 3: Optimal media composition for Pediococcus acidilactici.

\begin{tabular}{|c|c|c|}
\hline \multicolumn{3}{|c|}{ Optimal media composition concentration (mM) } \\
\hline Nutrients & $\begin{array}{c}\text { Optimal manganese } \\
\text { medium }\end{array}$ & $\begin{array}{c}\text { Optimal beef extract } \\
\text { medium }\end{array}$ \\
\hline $\mathbf{M n C l}_{\mathbf{2}}$ & $\mathbf{1 . 4 1 4 8}$ & 0.0253 \\
\hline Beef extract & $20 \mathrm{~g} / \mathrm{L}$ & $\mathbf{6 4} \mathbf{g} / \mathbf{L}$ \\
\hline Peptone $^{\text {MgSO }}$ & $10 \mathrm{~g} / \mathrm{L}$ & $10 \mathrm{~g} / \mathrm{L}$ \\
\hline $\mathrm{K}_{2} \mathrm{HPO}_{4}$ & 0.8111 & 0.8111 \\
\hline $\mathrm{Glucose}$ & 11.4 & 11.4 \\
\hline $\mathrm{C}_{2} \mathrm{H}_{9} \mathrm{NaO}_{5}$ & 11.1 & 11.1 \\
\hline $\mathrm{Yeast} \mathrm{extract}$ & 36.7 & 36.7 \\
\hline $\mathrm{C}_{6} \mathrm{H}_{8} \mathrm{O}_{7}$ & 14.6 & 14.6 \\
\hline
\end{tabular}

Note: Bold fonts indicate new nutrient concentration.

The average growth rate of effective bacteria in media fortified with different concentration of beef extract and manganese were calculated to identify the optimal media formulation. Based on the data of this experiment, it can be concluded that the highest growth rate was the media fortified with $64 \mathrm{~g} / \mathrm{L}$ beef extract with a growth rate of $0.145 \pm 0.025 \mathrm{~h}^{-1}$ compared to MRS control medium $\left(0.0479 \pm 0.01 \mathrm{~h}^{-1}\right)$ (Fig. 1).

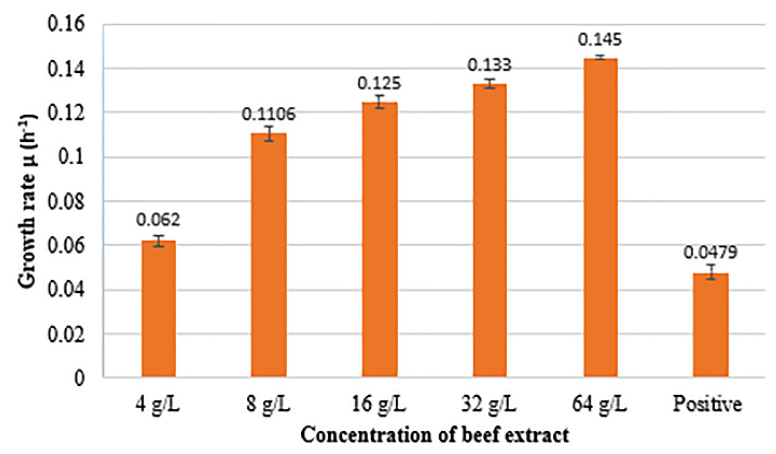

Fig. 1: Growth rate of Pediococcus acidilactici cultured in different concentrations of beef extract-fortified MRS media.

The optimized manganese medium with a concentration of 0.28 $\mathrm{g} / \mathrm{L}$ showed the highest growth rate of $0.1134 \mathrm{~h}^{-1}$ in comparison to positive medium with a growth rate of $0.0468 \mathrm{~h}^{-1}$ (Fig. 2). This indicates that as the volume of beef extract and manganese increase, the growth rate also increases. According to Fung [21], meat extract has a significant impact on the growth of $L$. acidophilus. Furthermore, Polak-berecka [11] study showed that a complex nitrogen source is vital for the growth of lactic acid bacteria. They also highlight that meat extract is label as the best complex nitrogen source compared to other nitrogen sources, in example peptone and yeast extract. This it because among others nitrogen sources, meat extract contains the highest amount of total nitrogen. In addition, the adequate amount of nitrogen source required by $P$. acidilactici can also support the pediocin production besides enhancing their growth condition [22].

Other than that, manganese ions have been confirmed by Lei Yu [23] to have an imperative effect on lactic acid production. This means that maximum bacteriocin production by lactic acid bacteria can be achieved by adding a certain amount of manganese in minimal cultivation time. Moreover, supplementation of manganese at an optimal concentration can boost the growth activity of Lactobacillus plantarium even though the role of manganese to increase plantaricin 423 by this microbe is still unclear. However, Charles and Kenneth [15] clarified that manganese might represent as the main electron acceptor for carbon-based oxidation in bacteria. A result from their study had exhibited that after some stages of sub-platting occurred, Alteromonas putrefaceins stopped growing in an area due to depletion of the manganese II oxide supply.

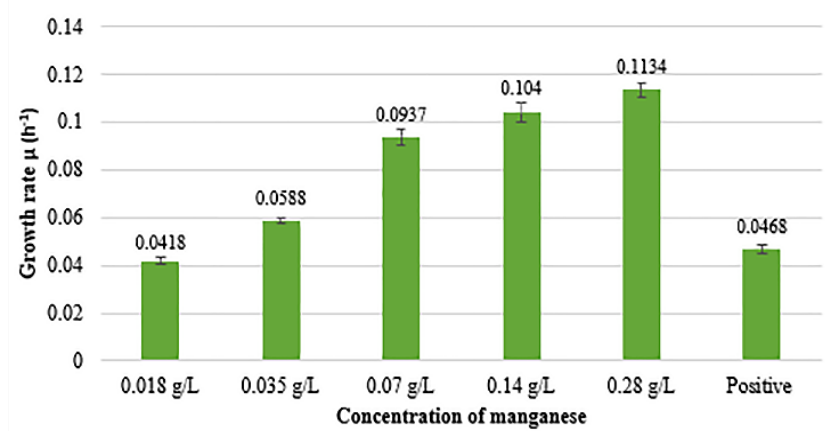

Fig. 2: Growth rate of Pediococcus acidilactici cultured in different concentrations of manganese-fortified MRS media.

Optimal media derived from the nutrient screening experiment (optimal and control or the non-optimal medium) were subjected to the subsequent reproducibility test via cultivation of effective microbes in $1 \mathrm{~L}$ flask to determine the differences in yield. It was observed that the optimized media fortified with $0.28 \mathrm{~g} / \mathrm{L}$ manganese and $64 \mathrm{~g} / \mathrm{L}$ beef extract yielded higher biomass in comparison to MRS control medium in 48 hours of cultivation (Fig. 3). It can be concluded that both tested nutrients provide greater bacterial growth performance as well as bacteria biomass productivity, hence, in agreement to research by Polack-Berecka [11] and Lei $\mathrm{Yu}$ [23] that additionally enhanced the production of bacteriocin produced by lactic acid bacteria although pediocin activity and yield determination were not conducted in this study.

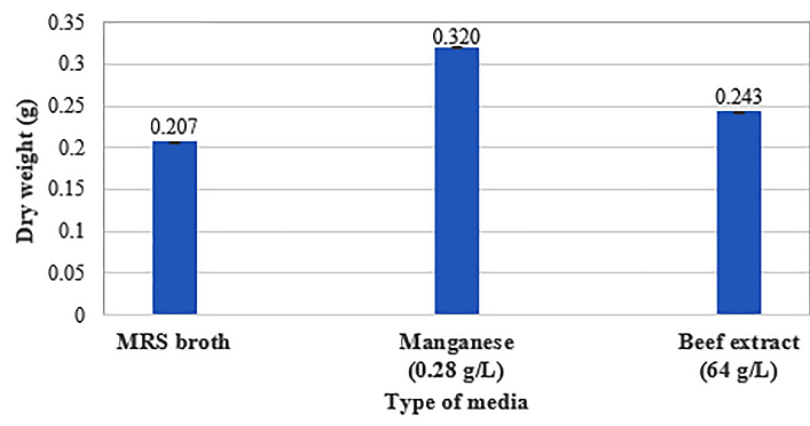

Fig. 3: Dry weight biomass of Pediococcus acidilactici cultured in different types of media.

\subsection{Optimization of culture medium to enhance the growth of Photosynthetic bacteria using Automated Media Optimization System}

The optimal glucose and yeast extract medium composition was shown in Table 4. The carbon source was glucose instead of DLmalic acid used in $\mathrm{HCH}$ medium. As for the nitrogen and vitamin sources, Baker's yeast extract was used. Five different concentrations were tested, but the result indicated that $1.6 \mathrm{mM}$ of yeast extract was the best concentration required by the photosynthetic bacteria.

Table 4: Optimal media composition for Photosynthetic bacteria.

\begin{tabular}{|c|c|c|}
\hline \multicolumn{3}{|c|}{ Optimal media composition concentration (mM) } \\
\hline Nutrients & $\begin{array}{c}\text { Optimal glucose } \\
\text { medium }\end{array}$ & $\begin{array}{c}\text { Optimal yeast extract } \\
\text { medium }\end{array}$ \\
\hline $\mathrm{Na}_{2} \mathrm{EDTA}$ & 0.054 & 0.054 \\
\hline $\mathrm{MgSO}_{4}$ & 0.997 & 0.997 \\
\hline$\left(\mathrm{NH}_{4}\right)_{2} \mathrm{SO}_{4}$ & 7.6 & 7.6 \\
\hline $\mathrm{Trace}_{4}$ element & $1 \mathrm{ml}$ & $1 \mathrm{ml}$ \\
\hline $\mathrm{KH}_{2} \mathrm{PO}_{4}$ & 3.7 & 3.7 \\
\hline $\mathrm{K}_{2} \mathrm{HPO}_{4}$ & 1.7 & 1.7 \\
\hline $\mathbf{G l u c o s e}$ & $\mathbf{3 6 . 8}$ & 22.0 \\
\hline Yeast extract & 0.36 & $\mathbf{1 . 6}$ \\
\hline $\mathrm{CaCl}$ & 0.676 & 0.676 \\
\hline
\end{tabular}

Note: Bold fonts indicate new nutrient concentration. 
The growth percentage of photosynthetic bacteria showed positive growth. As highlighted in Fig. 4, the highest growth rate in terms of glucose fortification was shown at the concentration of 36.8 $\mathrm{mM}\left(0.25 \pm 0.002 \mathrm{~h}^{-1}\right)$ compared to positive control medium was at $0.19 \pm 0.02 \mathrm{~h}^{-1}$ with $\mathrm{p}<0.05$ in one-way ANOVA test.

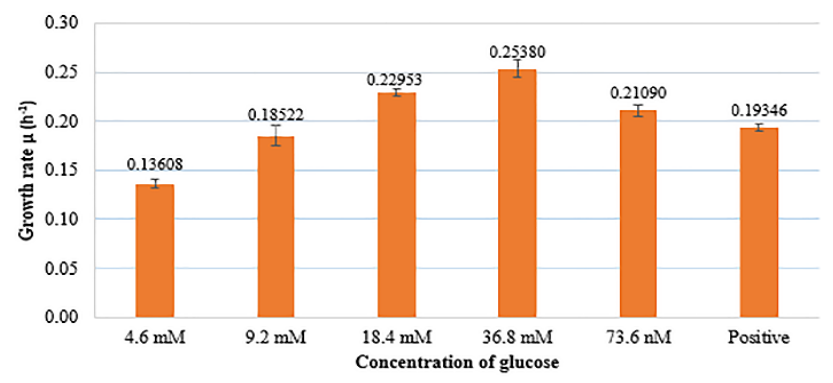

Fig. 4: Growth rate of Photosynthetic bacteria cultured in different concentrations of glucose-fortified $\mathrm{HCH}$ media.

The best growth assessment of photosynthetic bacteria in various yeast extract fortification (refer Fig. 5) was observed at $1.6 \mathrm{mM}$ concentration with a growth rate of $0.27 \pm 0.01 \mathrm{~h}^{-1}$, as opposed to the control medium with a growth rate of $0.19 \pm 0.02 \mathrm{~h}^{-1}$ in oneway ANOVA test.

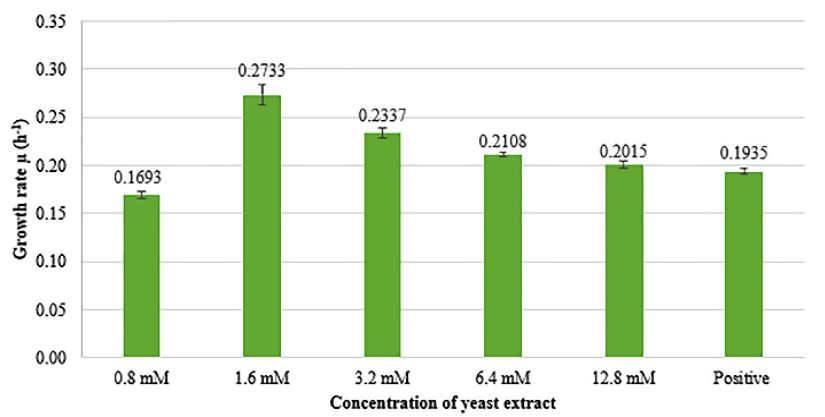

Fig. 5: Growth rate of Photosynthetic bacteria cultured in different concentrations of yeast extract-fortified $\mathrm{HCH}$ media.

The growth increment of the photosynthetic bacteria in the glucose-fortified medium showed 1.32 times higher and 1.42 times higher for the yeast extract-fortified medium in comparison to the positive control medium. This current data was coherent to the works conducted by Zhao [13]. They had reported that substitution of yeast extract and carbon source optimization effect resulted in an increment of bacterial yield up to 1.2 times and can be conducted at minimal cost. The optimization of glucose and yeast extract are important as the glucose provide an ideal carbon source as well as yeast extract usually used as growth stimulants or growth factors for bacteria. The nutrients contained in the yeast extract comprises of high level of protein, multivitamin B and minerals are necessary for the microbial cell development [12]. The determination of the correlation between the bacteria growth performance and biomass productivity can be ascertained via the determination of dry weight. The absorbance $\left(\mathrm{OD}_{660}\right.$ as a proxy of cell number) of the photosynthetic bacteria was taken by using a spectrophotometer. The photosynthetic bacteria were then conducted for a reproducibility test in a $1 \mathrm{~L}$ flask to obtain a sufficient amount of biomass yield. Hence, positive correlation could be derived from both of the nutrients modulation works. For the glucose-fortified experiment, the biomass productivity was 0.167 $\pm 0.001 \mathrm{~g} / \mathrm{L}$ and the percentage difference was $11.3 \%$ higher than the control medium. While the optimized concentration medium of yeast extract yielded $0.163 \pm 0.02 \mathrm{~g} / \mathrm{L}$ of dry weight with percentage increment of $8.73 \%$ higher than the control medium $(0.150 \mathrm{~g} / \mathrm{L})$. The dry weight determination for photosynthetic bacteria was conducted in 18 hours of incubation (Fig. 6).

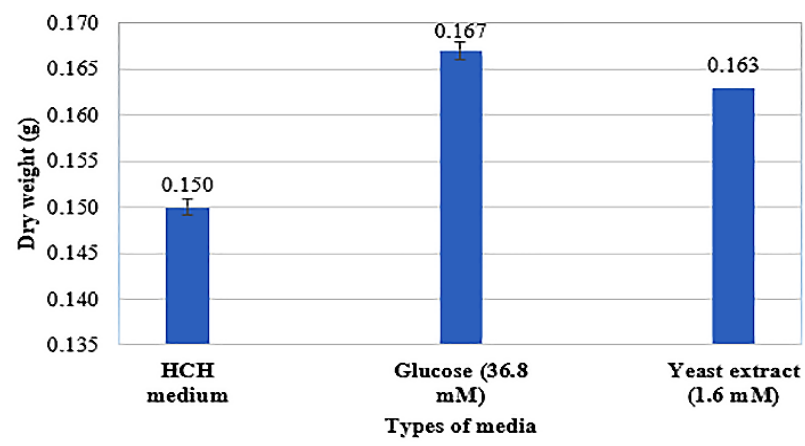

Fig. 6: Dry weight biomass of Photosynthetic bacteria cultured in different types of media.

\section{Conclusion}

In this study, we provide a new method of improving cultivation medium using high throughput screening based - Automated Media Optimization System. A new improved cultivation medium for Pediococcus acidilactici and Photosynthetic bacteria was successfully formulated based on Screen 1 data and tested in $1 \mathrm{~L}$ flask culture in order to determine the growth and biomass of the effective microbe cultures. The specific growth rate reported in this study make up the average growth rate of all effective microbes cells in the culture. Highest growth rate and biomass dry weight of $P$. acidilactici were observed when in a high concentration of beef extract media $(64 \mathrm{~g} / \mathrm{L})$ and high concentration of $\mathrm{MnCl}$ media $(0.28 \mathrm{~g} / \mathrm{L})$ compared to MRS medium in 48 hours of cultivation. Also, photosynthetic bacteria cultivated in the new optimal medium of $36.8 \mathrm{mM}$ glucose and $1.6 \mathrm{mM}$ yeast extract shown a potential growth and biomass dry weight increment than $\mathrm{HCH}$ control medium in 48 hours of cultivation. To conclude, cultivation media and other environmental factors are imperative to achieve higher growth and biomass production of microbes. Furthermore, using an efficient and lower cost culture medium may reduce the economic cost for the cultivation of effective microbes. Determining optimal cultivation parameters (such as $\mathrm{pH}$, agitation and light intensity) and larger cultivation system (bioreactor) are essential areas for future research to ensure maximum productivity of effective microbes. A high number of replicates with multiple types and concentrations of nutrient tested could improve the statistical analysis of the study by increasing the accuracy and precision of the currently attained data. Also, EM's growth performance will be more understandable when several nutrients and/or more complex nutrient cocktails are experimented in chorus via nutrient interaction of Box- Behnken statistical design system.

\section{Acknowledgement}

This work was jointly supported by the Faculty of Applied Science, Universiti Teknologi MARA (UiTM) and Minister of Education (MOE) in the form of Fundamental Research Grant Scheme (Grant No. 49 (2015)). We would also like to express our gratitude to the Bellus Terra Sdn Bhd (supply of effective microbes) and the Faculty of Pharmacy Universiti Teknologi MARA Puncak Alam Campus.

\section{References}

[1] T. Gideon, \& Filed (2016, January 19). What are Effective Microorganisms? Retrieved December 4, 2017, from https://permaculturenews.org/2016/01/19/whatareeffectivemicroorg anism/

[2] Z. Zakaria, S. Gairola, \& N. M. Shariff, Effective microorganisms (em) technology for water quality restoration and potential for sustainable water resources and management, International Congress 
on Enviromental Modelling and Software, (2010), page 448, http://scholararchive.byu.edu/iemssconference/2010/all/448

[3] D. Kantanchote, T. Nunkaew, T. Kantha, \& S. Chairprapat, Biofertilizers from Rhodopseudomonas palustris strains to enhance rice yields and reduce methane emissions, Application Soil Ecology, Vol 100, (2016), pp. 51-161.

[4] D. Baida, M. Boukhemis, \& A. Amrane, Formulation and evaluation of a selective medium for lactic acid bacteria - validation on some dairy products. American Journal of Agricultural and Biological Sciences, Vol 5, No 2, (2010), pp. 148-153.

[5] S. Kumar, Textbook of microbiology (2nd ed.), JayPee Medical, (2012), pp:32-38.

[6] R. Kratz, Microbiology the Easy way, Barron's Educational Series. (3rd ed.), (2005), pp:119-220.

[7] A. H. Rose, Chemical Biology (2nd ed.), Springer, (2013), pp:73-79.

[8] F. Bumbak, S. Cook, V. Zachleder, S. Hauser, K. Kovar, Best practices in heterotrophic high-cell-density microalgal processes: achievements, potential, and possible limitations. Appl Microbiol Biotechnol. Vol 91, No 1, (2011), pp. 31-46.

[9] M. Pathak, \& D. Martiroshan, Optimization of an effective growth medium for culturing probiotic bacteria for applications in strict vegetarian food products, Functional Foods in Health and Disease 2, Vol 2, No 10, (2012), pp. 369-378.

[10] M. M. Patil, K. V. Ramana, \& A. S. Bawa, Statistical optimization of bacteriocin production by Pediococcus acidilactici a simple food-grade medium, Journal of Food Processing and Preservation, Vol 37, No 2, (2012).

[11] M. Polak-Berecka, A. Waśko, M. Kordowska-Wiater, Z. Targoński, \& A. K. Komar, Application of response surface methodology to enhancement of biomass production by Lactobacillus rhamnosus E/N, Brazilian Journal of Microbiology, Vol 42, No 4, (2010), pp. 1485-1494.

[12] I. M. P. L. V. O. Ferreira, O. Pinho, E. Vieira, \& J. G. Tavarela, Brewer's Saccharomyces yeast biomass: characteristics and potential applications. Trends in Food Science and Technology, Vol 21 No 2, (2010). 77-84.

[13] W. Zhao, C. He, \& G. Zhang, Culture medium optimization for photosynthetic bacteria, Advanced Materials Research, Vol 113 No 116, (2010), pp. 1443-1446.

[14] E. I. Madukasi, H. Chunhua, \& G. Zhang, Isolation and application of a wild strain photosynthetic bacterium to environmental waste management, International Journal Environmental Science and Technology, Vol 8, No 3, (2011), pp. 513-522.

[15] C. R. Myers, \& K. H. Nealson, Bacterial manganese reduction and growth with manganese oxide as the sole electron acceptor, Science, Vol 240, No 4857, (1988), pp. 1319-1321.

[16] H. Nel, R. Bauer, E. Vandamme, \& L. Dicks, Growth optimization of Pediococcus damnosus NCFB 1832 and the influence of $\mathrm{pH}$ and nutrients on the production of pediocin PD-1, Journal of Applied Microbiology, Vol 91, No 6, (2001), pp. 1131-1138.

[17] K. Todar, (2017). Textbook of Bacteriology. Retrieved from http://www.textbookofbacteriology.net/index.html

[18] N. Pfennig, Photosynthetic bacteria, Annual Review of Microbiology, Vol 21, No 1, (1967), pp. 285-324.

[19] K. A. Radzun, J. Wolf, G. Jakob, E. Zhang, E. Stephens, I. Ross, \& B. Hankamer, Automated nutrient screening system enables highthroughput optimization of microalgae production conditions, Biotechnology for Biofuels, Vol 8, No 65, (2015), pp. 1-17, available online:

https://biotechnologyforbiofuels.biomedcentral.com/articles/10.118 6/s13068-015-0238-7

[20] K. E. Thomas, \& P. S. Eric, Nutritional immunity beyond iron: a role for manganese and zinc. Current Opinion in Chemical Biology, Vol 14, (2009), pp. 218-224.

[21] W. Y. Fung, Y. P. Woo \& M. T. Liong, Optimization of growth of Lactobacillus acidiphilus FTCC 0291 and evaluation of growth characteristics in soy whey medium: a respond surface methodology approach, Journal Agriculture Food Chemistry, Vol 56, (2008), pp. 7910-7918.

[22] Neera, M. M. Patil, K. V. Ramana, \& A. S. Bawa, Statistical optimization of bacteriocin production by Pediococcus acidilactici in a simple food-grade medium, Journal of Food and Preservation, (2012), pp. 1-9.

[23] L. Yu, T. Lei, X. Ren, X. Pei, \& Y. Feng, Response surface optimization of L-(+)-lactic acid production using corn steep liquor as an alternative nitrogen source by Lactobacillus rhamnosus CGMCC 1466, Biochemical Engineering Journal, Vol 39, (2008), pp. 496502 